\title{
"HELP ME PULL THAT CURSOR" - A COLLABORATIVE INTERACTIVE FLOOR ENHANCING COMMUNITY INTERACTION
}

\author{
Peter Gall Krogh \\ Institute of design

\section{ABSTRACT}

\begin{abstract}
In this paper we describe the development, experiments and evaluation of the iFloor, an interactive floor prototype installed at the local central municipality library. The primary purpose of the iFloor prototype is to support and stimulate community interaction between collocated people. The context of the library demands that any user can walk up and use the prototype without any devices or prior introduction. To achieve this, the iFloor proposes innovative interaction (modes/paradigms/patterns) for floor surfaces through the means of video tracking. Browsing and selecting content is done in a collaborative process and mobile phones are used for posting messages onto the floor. The iFloor highlights topics on social issues of ubiquitous computing environments in public spaces, and provides an example of how to exploit human spatial movements, positions and arrangements in interaction with computers.
\end{abstract}

\section{Keywords}

Interactive floor, library, ubiquitous computing environments, spaces as interface, social computing, interaction design, designing for community interaction, video tracking.

\section{INTRODUCTION / MOTIVATION}

Much design and research effort within HCI have been put into supporting distributed communities e.g. family members being away or living apart from one another (Hutchinson 2003), geographically distributed fellow, or systems supporting the establishment of contact and formation of groups and communities between people not knowing one another on beforehand (Nielsen 2002). There is a growing interest in how to support and encourage social interaction between collocated people and how the physical surroundings e.g. (Wilde 2003) can be exploited in this regard. However, little work addresses how ubiquitous computing environments will go beyond spatially arranged devices as in e.g. (Streitz 1999) and take into account and exploit spatial qualities of physical rooms, spaces and places. The work and the prototype presented here are a step towards realising the concept of interactive spaces.

The user population addressed in the work presented here are the visitors of a central public library; people that do not necessarily know one another on beforehand, but might be interested in informal conversations and contact with other citizens. As one of the most profound institutions of a democratic society the public library primarily serves as a place giving every citizen unrestricted access to catalogued information and providing facilities for self-initiated life-long learning. But in doing so it also indirectly serves as a social space enabling awareness of fellow citizens and the pluralism that is equally important in maintaining a vivid democratic society. 
In the research project denoted "The Future Hybrid Library", which is an initiative in the multidisciplinary research centre for "Interactive Spaces" mixing competences within architecture, engineering and computer science, we've been exploring how ubiquitous computing environments that take into account specific spatial qualities could support and enhance the social aspects of the library. As we would like to have as many potential users as possible to be exposed to the developed system the entrance hall of the local central public library was picked as framework for the design of the system as well as location for a later three week period of evaluation. On the basis of the spatial qualities and functions of the room we chose to explore this by means of an interactive display on the floor.

\section{BACKGROUND (AND CHALLENGES)}

In his book, e-topia (Mitchell 2000), William J Mitchell starts out with a tale of the well and its importance in cities in the early days of civilisation. Beyond being water reserve the well also had a strong social attraction, as people would go there just to meet up, exchange goods, arrange marriages etc. To enable the cities to physically expand and to minimize the risk of diseases, water was put into pipes suffusing the whole city. Having direct access to water in each household made the practical role of the well obsolete, whereas the social needs remained the same. In response to these new social places e.g. cafes emerged. By means of the tale Mitchell asks the polemic question: "What will happen when information by means of broadband access to the Internet is "piped" into our households?" Will this be the death of e.g. the library? Which services and installations in the physical library will support the institution in maintaining its attractiveness and social role? In recent years libraries throughout the world have focused on delivering web-based services for its users. Along with the web-based services there has been a growing focus in the physical library on meeting the needs of the individual user, and her ability to find relevant material. Activities and approaches as these have resulted in a starvation of the attractions of the physical library beyond erecting evermore-impressive buildings and architectural statements of the importance of the physical library.

Through user studies, interviews with librarians and statistics on numbers of visitors (Magistratens 4. Afdeling, 2004, only in Danish) at the local municipality library, we've learned that the by-product of these activities among others has been a decreasing number of visitors at the physical library. Many needs of the user in regard of finding relevant material can be met through advanced search and reservation facilities on libraries web sites. In addition to this the general facilities on the Internet: search engines, user groups, etc. also seemingly meet the users' needs for finding information. Furthermore, the social space in the physical library has taken a swing towards being more focused on the individual. Independently, some users and librarians in our user studies even talked about the local library as having developed a supermarket-like atmosphere where people are indifferent to the whereabouts of others. Probably this can be traced back to the increased focus of the library on serving the individual user supporting individual learning rather than providing a space for social gathering, activities and public awareness.

To summarize, the experienced social value of the public library shows tendencies to decrease. Visitors and librarians are becoming more and more focused on serving individual needs, efforts and tasks that obscure the view and attention to support and develop the social role of the library. To regain and strengthen the democratic role of the library it is necessary to devote more effort into the social aspects and activities of the library. New architectural monuments of the library and enhanced ways of efficiently organising the collection of materials are not enough to ensure the continued community-integrating role of the library. The design of computer systems also has to address the social challenges that the library is expected to meet. 


\section{RELATED WORK}

In order to address the challenges mentioned above the work presented here draws upon work in three areas: architectural design, ubiquitous computing and designing for community interaction. Furthermore, the interrelations of the three areas are explored in order to pursue the realisation of interactive spaces.

From a perspective of architectural design, the design of physical spaces, most of the work within ubiquitous computing has either worked on furniture-sized installations (Grønbæk 2001) following the concept of roomware (Streitz 1999) or generally applying the scheme of "tabs, pads and boards" initially described in (Weiser 1999). The only architectural element in these prototype environments that aims to transgress the affordances of furniture to become actual room-sized elements and interfaces are walls embedded with display facilities e.g. (Johanson 2002). The vertical orientation of large displays positioned to be touch by hand, makes it fairly easy to adopt many of the wellestablished ideals within HCI e.g. direct manipulation (Schniederman 1987) whereas interfaces that are hard to touch directly by hand e.g. ceilings and floors are less explored as interactive surfaces.

Interactive floor surfaces are typically experimented on in dance and performances like set-ups e.g. the prototype Magic Carpet (Paradiso 1997) and Litefoot (Fernstrom 1998). The prototypes are sensor intensive environments for the tracking of people's movements of feet and in the case of the Magic Carpet the sensor floor has been supplemented with sensor technologies for tracking the movements of the upper body and arms. To serve different shaping and sizes of an interactive floor the Z-tiles concept (McElliot, et al. 2002) was developed. As the above-mentioned systems the Ztiles interactive floor is based on sensor technologies. Input from the interaction technologies is used to control and manipulate sound providing the idea of playing an instrument with your body movements. Another system exploring multi-user spatial interaction by means of an interactive sensor-based floor is the Virtual Space project (Leikas et al. 2001). The sensor technologies are in this case used to enable spatial interaction and control of a computer game projected on a vertical positioned display. Another approach to enable spatial interaction is the use of video tracking e.g. the commercially available eyetoy game. http://au.playstation.com/ps2/hardware/eyetoy.jhtml.

Most of the work with designing for community interaction uses computer interfaces to mediate distributed activities enabling awareness of distributed people's interests and whereabouts e.g. (Büscher et al.). Increasing effort has been directed towards enabling community interaction among collocated users (Churchil 2004). As computers and computer interfaces for community interaction become an increasingly influential part of our everyday lives (Grinter 2002) we see a need for addressing issues related to the experience of the social qualities related to the experience of collocated users. These concerns are intensified as computer interfaces transgress traditional interfaces and become embedded in the physical surroundings and spaces enabling groups of collocated people (Huang 2004) to simultaneously interact with the systems accessible or as experienced in awareness facilities in office spaces. From our point of view this body of work lacks to take the spatial qualities of the physical environment sufficiently into account in regard to of how systems might be operated and appropriated in use.

The new Seattle Central Library (Koolhaas 2004) is, a part from being an impressive architectural statement of the library as institution, also a refreshing example of how the need for social spaces and their nature can have just as strong impact on the design of the building as ensuring efficient organisation of the collection of media typically has when designing libraries. Though the use of computer systems and their physical materialisation in the new Seattle Central Library is fairly traditional with huge amounts of personal computers, floor spaces as "the living room" on $3^{\text {rd }}$ floor and "the mixing chamber" on $5^{\text {th }}$ floor, indicate an increased awareness of the social role of the library. But how would these floor spaces have materialised architecturally if they from the early design stages were thought of as ubiquitous computing environments, encouraging social interaction. 
We see a need for including spatial concerns in the design of systems and interfaces for community interaction that goes beyond the mediation of distributed activities to include the experience of the collocated user. Furthermore, there is an unexplored potential in including more playful aesthetic ways for interacting with these systems. From our point of view experiments taking on this challenge could be informed by approaches to aesthetic interaction as promoted by (Petersen et al. 2004).

\section{DESIGN RATIONALE AND AIMS}

In the following we will present our rationales and aims of the prototype design. The development of this prototype has two basic aims. The first is to facilitate a space for communication and collaboration, based on the exploitation of user knowledge and curiosity. The system should not announce itself as a community supporting system. It should merely be a trigger for collocated people to start talking and engaging with one another. The second aim is experimenting with collaboration on interactive floor surfaces with no need of special input devices apart from being present in the physical library. This is done in order to design an interactive system that can be appropriated by most of the broad range of people visiting the public library every day. These users include all ages, genders, races and professions e.g. children, disabled, students, mothers with bags full of books etc. For more advanced interactions we will experiment with mobile phones as $90 \%$ of all Danish families have minimum one mobile phone (Statistics Denmark 2004)

The prototype is to be located in the entry area of the local central library, a transit space that is approached by the users from all directions. To keep the spatial qualities of this transit area it is important to ensure visual overview of the adjacent spaces. In addition to this public spaces are characterized by people with many different doings and different attitudes towards disruptions in the public realm (Gehl 1987). To comply with this we will experiment with floor interaction that in many aspects will not alter the physical space.

Designing for public space requires certain considerations regarding the robustness of the system, which should result in an interactive system without any direct contact with the hardware.

By introducing the prototype we want to inspire to the change of the communication style of the library. Today most library users have interpersonal interactions with only the librarians, asking them for advice or references to books. The local central library is fairly visionary with respect to introducing technologies to make the daily handling of books and other materials more efficient. Thus they have introduced self-service check in- and out of materials, and recently also self-service check-out of reserved items. This means that the interactions between users and librarians have been minimized, and the library is decreasing its need for interpersonal interaction. In the design process library staff and mangers expressed the need to counter this trend by creating facilities and a space for informal exchange of knowledge among users, and encourage the transformation of the library into a more vivid social space. Addressing this became one of the key design issues of the developed prototype.

\section{THE PROTOTYPE}

On the basis of the above identified challenges and needs a prototype was developed: an interactive floor for communication between users of the library named iFloor. We will describe the iFloor by looking at separate elements of the design: the general setup, the technology, the graphic user interface, bodily interaction and interaction by adding content. Basically the iFloor is an interactive floor that affords users individually or in collaboration to browse and discuss projected questions and answers produced by the users themselves, through the movement and position of their body. By the use of a mobile phone or an email client questions and answers can be posted on the floor. 


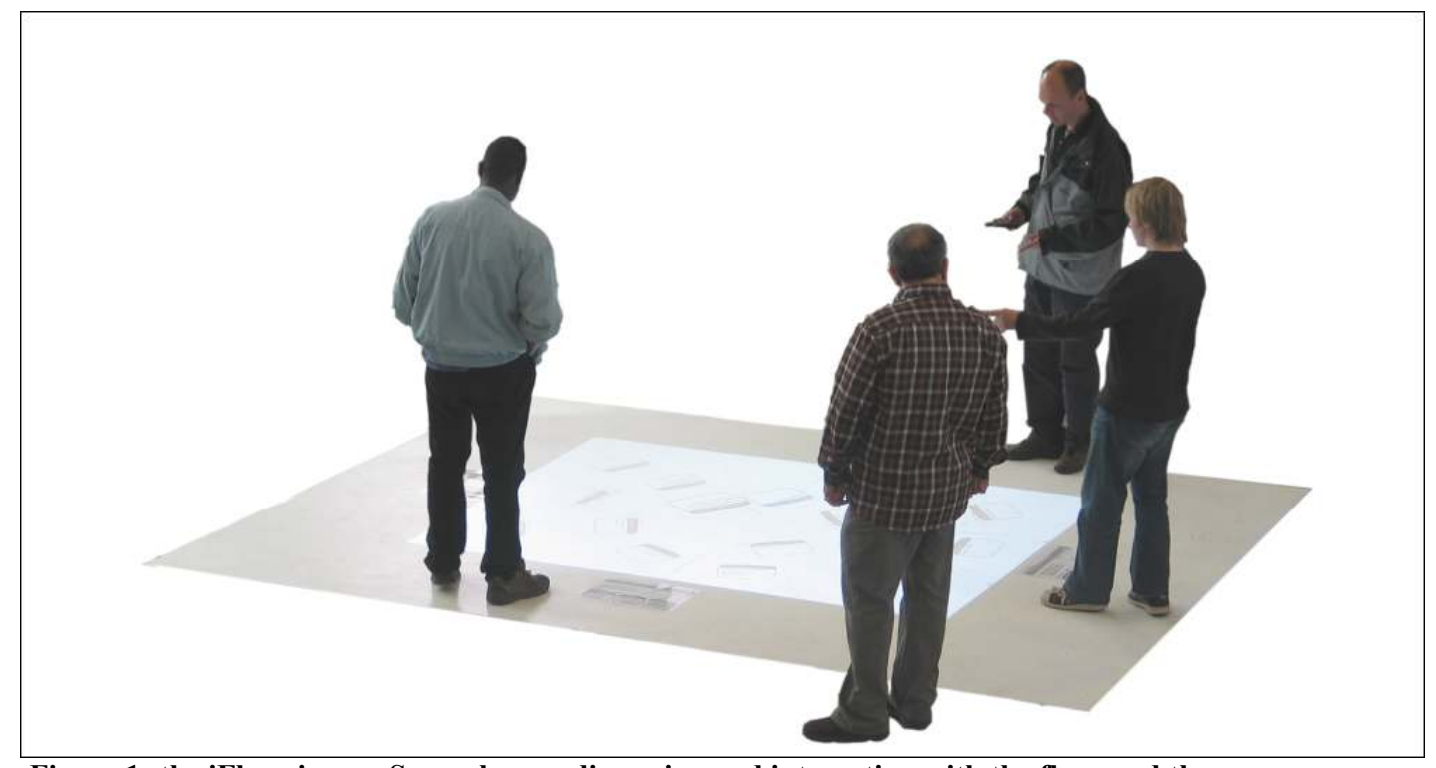

Figure 1: the iFloor in use. Several users discussing and interacting with the floor and the man on the opposite side of the floor is writing a message to the iFloor using a mobile phone

\section{Technical setup}

The system consists of a remote server for receiving and handling sms' and emails and administering questions and answers. Furthermore, a projector mounted on the ceiling is connected to a local computer for the display on the floor. Due to the requirement for system robustness, tracking technologies like e.g. interactive tiles (e.g. Richardson) were rejected because this would require the installation of a technology-intensive floor that would be vulnerable in the public space. Instead the floor interaction works on the basis of a video tracking system software (Valli 2004) analysing the rim of the interface based on a video feed from a web-cam mounted on the ceiling. The tracking of people's position and movement are sent from Retina to Macromedia Flash and translated into magnetic forces attracting the cursor. This solution has the advantage that all fragile parts are mounted on the ceiling and thereby removed from direct access. Using projections in bright daylight caused problems regarding the visibility of the display and the tracking. This was solved by using a powerful projector to project the graphic interface onto thin white PVC boards on the floor creating a clear projection image and giving a good sufficient contrast in the video feed for the blob analysis and threshold tracking done in Retina.

\section{Bodily interaction and the interface}

Due to the novel interaction explored in the prototype and the unprecedented facilities offered by the prototype the graphic user interface had to be very simple and clear.

Technical tests showed that the precision in tracking we got from a simple web cam was enough to keep track of at least 15 people at one time in a 5 meters by 4 meters rectangle. Diminishing the possibility of users entering the projection and thereby casting shadows on the content we only used data from the tracked persons in a one meter band surrounding the display. By using a visual feedback in form of a projected string connecting the cursor and the user while being in the tracked AJIS Special Issue 
area, people could see that they were taking part in the interaction. As soon as they entered the projection on the floor the string would disappear and they would have no influence on the system. We used the coordinates from the tracked persons to calculate the movement of a graphical element representing a shared cursor. The cursor had its initial position in the centre of the floor but as soon as the camera detected a person in the tracked area, the string would connect user and cursor and the cursor would start moving towards the user. Stepping out of the tracked area would instantly make the cursor move towards the centre. In this way the system got very responsive supporting various playful ways of interacting with the cursor both as an individual and in collaboration e. g. by spreading out hands and feet one can obtain up to five strings giving five times the power of a user standing straight.

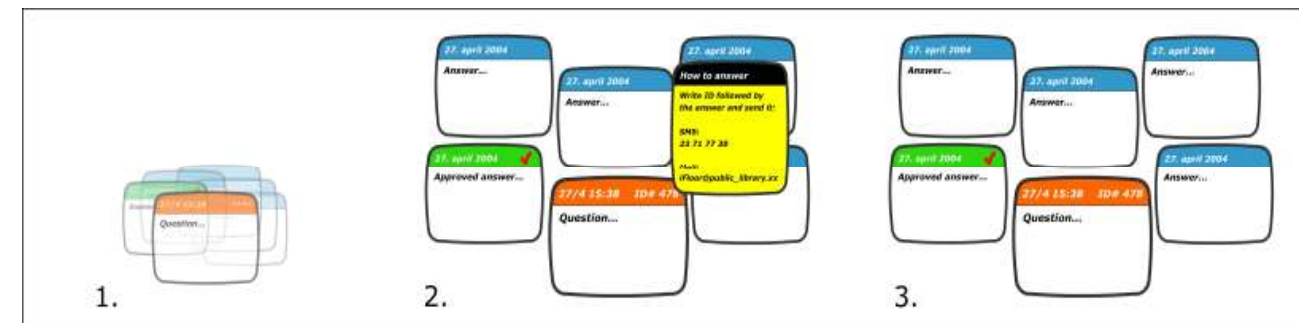

Figure 2: The unfolding of a question. A tool-tip provides the relevant instructions for replying. The green answer-box is an approved answer from a librarian.

The maximum number of questions on the floor was set to 15 due to screen space and text readability. Each question carried a time stamp that was used to exchange new questions with the oldest time stamp on the floor. We designed colour coded graphic elements as containers for the questions and answers. The fact that the floor was approached from all directions challenged the common layout of interfaces traditionally approached from one direction. To comply to that the questions were arranged in a circular array around the centre of the floor to provide equal access and readability of the display from all directions along the rim. Intentionally, this encouraged users to walk around the floor in order to read all questions or ask others about questions on the other side of the floor. In experimenting with an alternative to double click on the floor we used the event where the cursor entered a question to trigger an animation unfolding the question and revealing its specific ID number. If the question had been responded to earlier, these would fold out from behind the question enabling the user to read up to five different suggestions. The questions could be read at all times but users had to move and negotiate the cursor around to read the answers related to the questions. This was deliberately chosen to encourage users to communicate and negotiate on the movement of the cursor.

By designing the cursor to slow down when entering a question we gave users time to read the question and related answers and get the ID number. When leaving the unfolded question the cursor speed raised and an animation contracting the question and answers was triggered.

During the evaluation period in the library we made ongoing improvements and changes to respond to interviews and user observations. The changes were made both to respond to expressed user needs as well as to try out new features. Two changes are mentioned in particular here. In order to make the prototype more self-explanatory tool tips-like would evolve from the questions when the cursor would enter a question. The tool tips described exactly in three bullets how to answer the specific question either by mobile text messaging (SMS) or e-mail. Another change was made to encourage the librarians to take ownership of the prototype and to give their answers more integrity by developing an approved answer - colour coded in green - that could be posted through the same web interface that was used to clean up the floor for offensive questions and answers. 
To experiment with different ways of having users interact with the system we tried making the cursor respond to movement instead of position. This resulted in a dance-like performance to get the attention of the cursor but making precise interaction very difficult.

Finally, we tested the implementation of cursor-speed adjusting facilities mediated by icons. By adding small symbols in the corners of the display representing two speed up and two speed down facilities, users could move the cursor to an icon and through feedback from a counter see the change in cursor speed. This was tried out to add a higher degree of interaction but the feature also had a tendency to create chaos on the floor by unfolding all questions in seconds because of the speed.

\section{Adding content}

To compose new questions users were requested to use either an email client or their mobile phone as input device. By using mobile phones and SMS we could enable people to interact with the system without any specially designed gadgets supported by the library or the prototype itself. Questions could be posed by sending a SMS containing a question on max 120 characters to the iFloor phone number. About ten seconds after sending the question the user would get feedback in form of a SMS saying "thank you for your question, you will receive answers as soon as they arrive, regards iFloor". After that the oldest question and related answers disappear from the graphic interface making room for the new question to emerge on the floor during an animation clearly showing that new content has entered. Responding to a question is done by entering the ID number revealed from an unfolded question in a SMS or e-mail followed by the answer. This creates a new answer that is nested to the question. In order to give visual feedback to users around the floor on changes in content and to promote curiosity in exploring the floor animations were implemented.

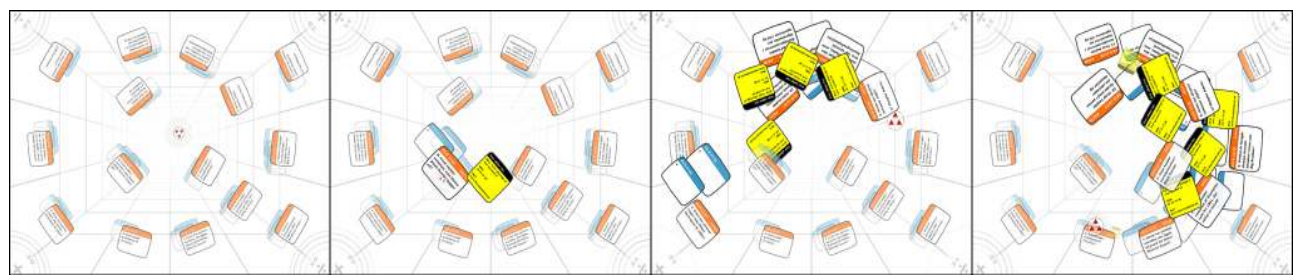

Figure 3: As the cursor enters the questions they unfold and reveal the ID-number and related answers. Too high cursor speed will activate neighbouring questions and responses creating a confusing overlapping pool of messages.

\section{EVALUATION}

The evaluation with users in the library context was conducted with emphasis on qualitative interviews and observations of users. In our observations we focused on relevance of the prototype and on learning what users experienced when interacting with the system, on the expense of statistics. During the three weeks of evaluating the prototype, we had several users experimenting with the installation. Sometimes we stayed in the background to leave the users to figure out the interaction by themselves, and at other occasions we introduced the prototype to the users in order to engage in dialogue about how the installation was perceived. This way we had both informal talks with users and formal interviews conducted after users had worked or played with the prototype. In the course of the three weeks we also made observational videos of the space where the prototype was installed in order to see how people reacted to it, and how it affected people moving through the space. 
Another source in the evaluation was the feedback from the library staff on how they experienced the support of users interacting with the floor and their reflections on how it contributed to the traditional library context. Along with the feedback from the user interviews, the librarians' feedback was the starting point of redesigning and altering aspects of the floor during the three weeks and in order to enhance a walk-up-and-use experience and make the prototype more self-explanatory, as explained in the prototype section.

As a part of the qualitative evaluation we also invited a $7^{\text {th }}$ grade school class for a one hour quiz game. We posed the questions and they were supposed to find the answers by using the traditional search facilities provided by the library. With 25 pupils in the class it was a good way of seeing how the system would react to a maximum load of input. The experiences from this test emphasized the fact that even though the technology in theory could support an unlimited number of participants, the social and physical space set a certain limits to that number. The negotiation part of interacting with the prototype and trying to figure out how the tracking worked could not surpass the competitive element of the quiz game, so the prototype was often blocked by too many inputs. If the video tracking software can see users diagonally across from each other or, as in this case, all the way around the periphery of the floor, the cursor simply stops in a dead zone of equally balanced pull.

The kids in the class were especially fast at adopting the system, and quickly used the floor beyond its intended use, as they started to post teasing remarks and other messages to the school mates. This way the floor expanded into a different kind of communication surface of graffiti-like tagging and personal exhibition.

\section{REFLECTION}

The iFloor challenges several interaction paradigms (Svanæs 2000) as they are difficult to translate these into interacting with a floor.

In the three week period of evaluation and redesign of the prototype at the local central library we learned that the questions posed typically would be in the category of seeking advice or tips and tricks on every day things as, how to un-lock ones mobile phone, or where to find the best and cheapest printer. It came to work at bit like the notice board found in local supermarkets; however, in this case the communication was not about runaway cats and baby carriages for sale but knowledge exchange between users at the library. Furthermore, as the floor was residing in the entrance and exit part of the library it came to work like a "sleeping policeman", causing people to stop and to start chatting about the questions and answers on display, and taking the opportunity to participate in the process by posing new questions and responding to the ones in the display. Furthermore, the playful way of navigating the interface was found very intriguing by the visitors and definitely also facilitated the process of making people talk to one another.

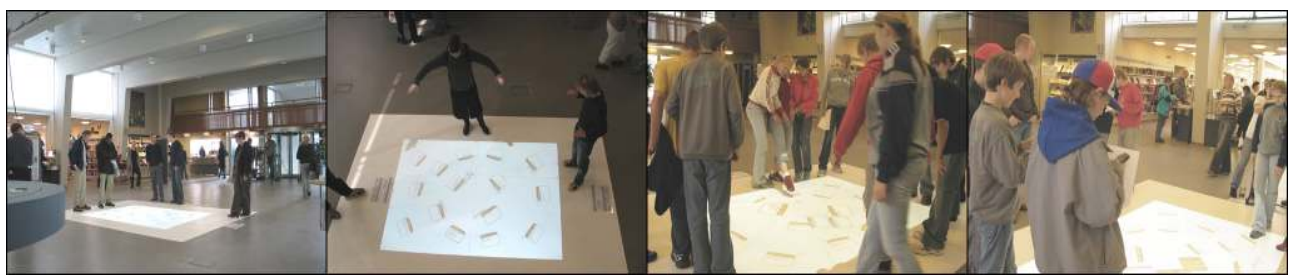

Figure 4: The iFloor in the library.

After having discovered the interaction mode and the idea of the system, most people are enthusiastic about the technology and idea of use. When asked, most users were capable of thinking of many other places where a physical/digital bulletin board-like functionality could be helpful or 
interesting. E.g. a group of student teachers had an idea for using it as a means of teaching because of its synergetic effect between play and serious content.

\section{SPATIAL INTERACTION}

\section{Proximity}

Using the body as the means for interaction is to many people a very provocative and challenging idea. It seems the single-user-in-front-of-a-desktop paradigm has been thoroughly accepted by the general public. Through the iFloor prototype we are experimenting with new principles for interacting with augmented floor surfaces. Walls and all kinds of furniture (e.g. Dunne 2001) have been used as interactive artefacts or displays, but using the floor surface as a collaborative multi-user surface sets design challenges as to how to point click and select content on the floor. Being out of reach in most situations, the floor is not a surface for direct manipulation (Schneiderman 1987). On the other hand, a potential input that is always available is if a user is able to view the floor he will be in the physical vicinity of it, so by using video tracking we can relate the floor to the user and afford interaction.

This physical proximity is translated and used to orient the interface to the user. The question boxes are rotated in relation to the centre of the floor to ensure readability no matter from where the user will approach the display. At the same time this rotation encourages the user to walk around the floor to read the other questions, thereby discovering that the cursor is attached to her by a string and responding in real-time to movements. This sets of an exploration of the interaction and in several cases we saw users in the library trying out different ways of enhancing their ability to attract the cursor by e.g. joining other users or spreading out arms and legs.

\section{From private to public displays}

Sending questions and answers to the iFloor are done by SMS or via emails. This causes an interesting flow from using a public display in collaboration to using your private mobile phone or walking away to a computer, sometimes while still discussing the answer with a friend around the floor. The mobile phone becomes a remote control or a wireless keyboard for the shared display on the floor, causing a mix of private and public space.

Utilizing the mobile phone in the iFloor concept also means that the library extends its sphere of influence into the city, as you can pose questions or receive answers anywhere. The knowledge sharing that we try to establish in the library goes beyond the physical constraints of the library. However, the core of the community is still the collocated people at the library, since it is only the people present round the floor that can read and get access to the ID-numbers and thereby answer the question.

\section{SOCIAL ISSUES}

\section{Social Navigation}

During the first days of setting up in the library, we walked around the floor to ensure it was running properly. This attracted many users who interestedly started using the system. But when we stepped away from the floor the interest decreased. Not for the individual users currently engaged in interaction but as a general trend for people arriving at the library. The floor, we decided, did not convey its potential use strongly enough. It looked attractive and interesting at first glance but potential users rapidly lost interest as they were unable to figure out how to use it and what the point of the interaction was. We changed the set-up by placing A3 sized posters on the three sides of the 
floor where people would approach it. Thereby we allowed an opportunity to observe and learn what the system was about before stepping onto the floor and interacting. Even with this stepping stone approach, users were still hesitative to jump onto the floor and we sometimes had to jumpstart interaction simply by being present on the floor conveying a use pattern and the fact that the system was safe (and even fun) to use. When on its own, it seemed to us, the prototype was too unfamiliar for most people and the rate of how many walked up and experimented with the floor more than halved.

As described in (Höök et al. 2003) it is very important for a physical place as well as for a digital to convey it use context through the social interaction taking place. When designing a place that is both physical and digital and unfamiliar to the potential users, it is important somehow to provide the users with a possibility to gradually approach the system in a socially safe way. From observing how many people are using the floor and especially what they are doing, one can decide whether or not to participate. As a general rule when people are having fun or are deeply engaged in interacting it seems far more interesting for outsiders to try for themselves.

\section{Negotiation and collaboration}

When users were experimenting with the prototype, we often saw problems with sharing the cursor. In most cases when the users did not know each other, the negotiation that had to take place in order to move the cursor to the desired location was limited. If a user finds a question interesting he will have to ask the other users around the floor to work with him to move the cursor to the question or tell them to get off the floor, which happened almost as often as the first approach. Contrary to this, users were quite helpful explaining how to interact with the system to other users approaching the floor. In one case an elderly man had experimented with the floor and read the poster beside it, and was able to introduce the conceptual idea and use of the floor to a family of three. After this introduction they explored both what could be done with the video tracking and when using the SMS-service. The single-user perspective is so deeply imbedded into users when it comes to using digital technology, that it seems surprising that a display and a cursor is addressing several users in 360 degrees. When approaching the iFloor a user discovers her influence on the system as a string is "attached" to her and follows her around as she walks round the floor to read the questions. When entering the floor, users will inadvertently disturb anyone else who might be doing something purposeful with the cursor. In this way the interaction with iFloor invites or even demands users to collaborate in order to control the interface. By setting up such "forced" collaboration, we wanted to create a hidden opportunity for library users to establish contact with each other, however transitory these contact might be.

Finally, we observed several users, who did not know each other beforehand, discussing possible answers to questions. As with a dinner table, it is seemed socially acceptable to be talking with the people you are sharing a point of attention with, and collaboratively solve the problem.

\section{Play}

As users become more familiar with the interaction and figure out how the system is controlled, they can use the iFloor in a more playful manner. The iFloor can be manipulated to give more pull to a single user if he or she discovers that spreading out arms and legs will give more pull, as the video tracker sees more blobs and therefore "attracts" more strings to the cursor. This can give two or three users an opportunity to play with the floor and compete on who has the power to control the cursor. This game was often initiated when users were walking around the floor and noticed e.g. that they had strings "attached" to both their feet. The game became almost sport-like as it is your agility and stamina that will decide who can attract the most strings and win the cursor over. Often these games appeared almost like dance performances as users really got captivated and expressive in their effort 
to attract the cursor. Making teams could also be a way of competing. Sometimes users would also insist on the efficiency of something that did not have any effect on the system, like stomping or dragging the feet backwards as if the strings were physically attached to them. This, of course, makes sense in a direct translating of a physical string's affordances, and this was often how users experimentally appropriated the prototype.

\section{FUTURE WORK}

In continuation of the "Future Hybrid Library" project a related project has been launched called "The Children's Interactive Library". In this work we will advance the exploration of spatial interaction paradigms in relation to the social spheres in the children's library. In further development in the library context we will address the following issues for improving the iFloor prototype:

- Visual aging of questions to create a fast overview of new and old questions.

- The relation to the physical surroundings e.g. using the floor for directing users to bookshelves related to their questions.

- Explore the use of the third dimension down in floor.

- Using gestures to improve the bodily interaction.

As the technical solution proved to be fairly robust we believe that similar installations could be applied in other domains of the public space with a projectable floor material and the proper light conditions to do the video tracking e.g. as an interactive informative city map in transportation transit spaces supporting newcomers to get the latest information on events and happenings.

\section{CONCLUSION}

The iFloor prototype, as we have presented in this paper, experiments with new interaction modes for using floors as collaborative display and interaction surfaces. Novel interaction was achieved through the use of video tracking to extract the positions of the users around the iFloor, and thereby placing a shared cursor to navigate the posted messages. Questions and responses were posted onto the floor by using a mobile phone as remote keyboards. In order to support community and informal interpersonal interactions in the library the iFloor encourages users to collaborate and negotiate when interacting with the cursor and browsing questions. The installation of the iFloor contributed to the library's desire to change the library into a more social and communicative space. Through user studies we evaluated and improved the prototype and found that in addition to fulfilling the design aims from the library, the iFloor also supported users' curiosity through playful and spatial interaction.

\section{REFERENCES}

Büscher,M., Kramp,G, \& Krogh,P (2003) In formation: Support for flexibility, mobility, collaboration, and coherence. First International Conference on Appliance Design, Bristol, UK, 6-8 May 2003

Churchill, E., Girgensohn, A., Nelsen, L., Lee, A.: Blending Digital and Physical Spaces for Ubiquitous Community Participation. In Communications of the ACM February 2004/Vol. 47, No. 2

Dunne, A. \& Fiona R., Design Noir - The Secret Life of Electronic Objects, August / Birkhäuser, 2001

Fernström, M., Griffith, N: Litefoot - Auditory Display of Footwork. Proceeding of ICAD'98, Glasgow, Scotland (1998)

AJIS Special Issue

December 2004 
Gehl, J., LIFE BETWEEN BUILDINGS - Using Public Space, Van Nostrand Reinhold, New York, 1987

Grinter, R. E., Palen, L., I M everywhere: Instant messaging in teen life, Proceedings of the 2002 ACM conference on Computer supported cooperative work, November 2002

Grønbæk, K., Gundersen, K. K., Mogensen, P., \& Ørbæk, P. Interactive room Support for Complex and Distributed Design Projects. In proceedings of Interact 2001, Tokyo Japan, July 2001.

Huang, E., Russel, D.M., Sue, A.E: IM Here Instant messaging on large, shared displays for workgroup interactions. In Proceedings of CHI2004, Vienna. Pp $279-286$

Hutchinson, Mackay, Westerlund, Bederson, Druin, Plaisant, Beaudouin-Lafon, Conversy, Evans, Hansen, Roussel, Eiderbäck, Lindquist, Sundblad. Technology Probes: Inspiring Design for and with Families, In the ACM CHI 2003 Proceedings (2003)

Höök, K., Benyon, D., Munro, A.J., Designing information spaces: the social navigation approach, Springer-Verlag London, UK, 2003

Johanson, B., Fox, A., Winograd, T.: The Interactive Workspaces Project: Experiences with Ubiquitous Computing Rooms. IEEE Pervasive Computing Magazine 1(2), April-June 2002.

Koolhaas, R., Content, Taschen Verlag, Köln 2004 ISBN 3822830704 ,

Krogh, P., Grønbæk, K.: (2001) Architecture and Pervasive Computing - when Buildings and Design artefacts become computer interfaces, Nordic Journal of Architectural Research vol. 14 no. 3 2001, Århus DK, Pp. $11-22$

Magistratens 4. Afdeling, 2004 Forandringer og transformationer : oplæg til debat om indhold og struktur i de fysiske biblioteker i Århus i fremtiden : bibliotekspolitisk redegørelse. - Århus : Århus Kommune

Leikas, J., Väätänen, A. \& Räty, V. 2001: Virtual space computer games with a floor sensor control : human centred approach in the design process. In: Brewster, Stephen \& Murray-Smith, Roderick (Eds.) Haptic human-computer interaction : First international workshop, Glasgow, UK, August 31 - September 1, 2000, Proceedings. (Lecture notes in computer science; Vol. 2058) Berlin: Springer-Verlag. Pp. 199-204.

McElliot, L., Dillon, M., Leydon, K., Richardson, B., Fernstrom, M., Paradiso, J.: ForSe FIElds Force Fields for Interactive Environments. In Proceedings of Ubiquitous Computing 2002: $4^{\text {th }}$ International Conference Göteborg Sweden pp. $168-175$

Nielsen, R. Collaborative Spaces: Inhabiting Virtual 3D worlds, 2002, In: Virtual Space: The Spatiality of Virtual Inhabited 3D Worlds. Ed. Lars Qvortrup.

Paradiso, J., Abler, C., Hsiao, K., Reynolds, M: The Magic Carpet - Physical Sensing for Immersive Environments. Proceedings of CHI' 97, Atlanta, GA, USA (1997)

Petersen, M., Iversen, O. S., Krogh, P., Ludvigsen, M., Aesthetic Interaction - A Pragmatist's Aesthetics of Interactive Systems, proceedings DIS 2004 p.270-278, Boston, MA., USA

Richardson, B., Leydon, K., Fernstrom, M., Paradiso, J.A.: Z-Tiles: building blocks for modular, pressure-sensing floorspaces April 2004 Extended abstracts of the 2004 conference on Human factors and computing systems

Schneiderman, B.: Designing the User Interface: Strategies for Effective Human-Computer Interaction Addison-Wesley Publishers, Reading, MA) (1987),

Statistics Denmark, (in danish), Durable Consumer Goods 2004, Nyt fra Danmarks Statistik, nr. 183,2004

Streitz, N.A., et al. Roomware for Cooperative Buildings: Integrated Design of Architectural Spaces and Information Spaces. in CoBuild '98, Cooperative Buildings - Integrating Information, Organization, and Architecture. 1998. Darmstadt, Germany.: Springer: Heidelberg.

Streitz, N.A., Geißler, J., Holmer, T., Konomi, S., Müller-Tomfelde, C., Reischl, W., Rexroth, P., Seitz, P., Steinmetz, R. : i-LAND: An interactive Landscape for Creativity and Innovation. In: 
ACM Conference on Human Factors in Computing Systems (CHI'99), Pittsburgh, Pennsylvania, USA, May 15-20, 1999. pp. 120-127. ACM Press, New York

Svanæs, D. Understanding Interactivity: Steps to a Phenomenology of Human-Computer Interaction, monograph, Computer Science Department, ISBN 82-471-5201-0, NTNU, Trondheim, 2000.

Valli, A., RETINA - video tracking software available at http://alessandrovalli.com/retina/ (2004-06-

18)

Weiser M., Seely Brown J.; Designing Calm Technology. Mark Weiser and John Seely Brown. The 100 Show: the eighteenth Annual of the American Center for Design. Edited by Therese Rutowski. New York, NY: Watson-Guptill Publications, 1996; pp. 159-163.

Weiser, M., "Some Computer Science Problems in Ubiquitous Computing," Communications of the ACM, July 1993.

Weiser, M., The computer for the 21st century, ACM SIGMOBILE Mobile Computing and Communications Review, Volume 3 , Issue 3 (July 1999), Special issue dedicated to Mark Weiser, p. 3 - 11, 1999

Wilde D, Harris E, Rogers Y, Randell C, ( 2003 ) The Periscope: Supporting a Computer Enhanced Field Trip for Children. 1AD (First International Conference on Appliance Design), May 6-8th, 2003, HP Labs, Bristol. Also to appear in Personal and Ubiquitous Computing Journal

\section{ACKNOWLEDGEMENTS}

We would like to thank colleagues in the Centre for Interactive Spaces for comments on the prototype and in particular Kaspar Rosengren Nielsen for programming the interface, Niels Olof Bouvin for programming and administering the server part. We would also like to thank Kaj Grønbæk for useful comments on the paper.

\section{COPYRIGHT}

[Peter Gall Krogh, Martin Ludvigsen and Andreas Lykke-Olesen] (C) 2004. The authors assign to $\mathrm{OZCHI}$ and educational and non-profit institutions a non-exclusive licence to use this document for personal use and in courses of instruction provided that the article is used in full and this copyright statement is reproduced. The authors also grant a non-exclusive licence to OZCHI to publish this document in full in the Conference Papers and Proceedings. Those documents may be published on the World Wide Web, CD-ROM, in printed form, and on mirror sites on the World Wide Web. Any other usage is prohibited without the express permission of the authors. 